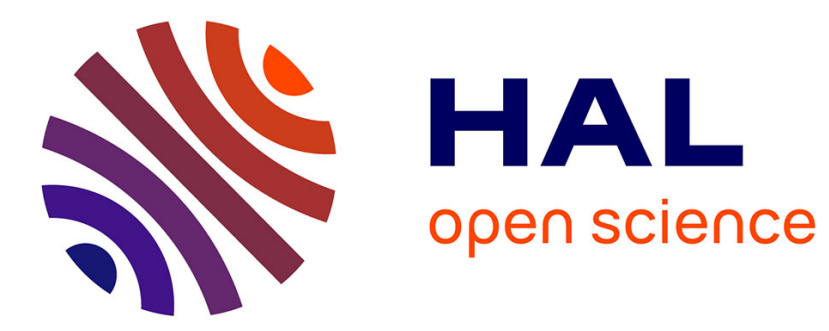

\title{
In-situ formation of barium ferrite in iron-doped "tetragonal tungsten bronze": Elaboration of room temperature multiferroic composites
}

Elias Castel, Michaël Josse, François Roulland, Dominique Michau, Lydia Raison, Mario Maglione

\section{To cite this version:}

Elias Castel, Michaël Josse, François Roulland, Dominique Michau, Lydia Raison, et al.. In-situ formation of barium ferrite in iron-doped "tetragonal tungsten bronze": Elaboration of room temperature multiferroic composites. Journal of Magnetism and Magnetic Materials, 2009, 321 (11), pp.1773-1777. hal-00381988

\section{HAL Id: hal-00381988 \\ https://hal.science/hal-00381988}

Submitted on 6 May 2009

HAL is a multi-disciplinary open access archive for the deposit and dissemination of scientific research documents, whether they are published or not. The documents may come from teaching and research institutions in France or abroad, or from public or private research centers.
L'archive ouverte pluridisciplinaire HAL, est destinée au dépôt et à la diffusion de documents scientifiques de niveau recherche, publiés ou non, émanant des établissements d'enseignement et de recherche français ou étrangers, des laboratoires publics ou privés. 


\title{
In-situ formation of barium ferrite in iron doped "tetragonal tungsten bronze”: Elaboration of room temperature multiferroic composites
}

\author{
E. Castel', M. Josse , F. Roulland, D. Michau, L. Raison, and M. Maglione
}

ICMCB-CNRS, 87 Avenue du Docteur Schweitzer, 33608 Pessac cedex, France

* To whom correspondence should be addressed: josse@icmcb-bordeaux.cnrs.fr

\begin{abstract}
Recent studies of ceramics of formula $\mathrm{Ba}_{2} \mathrm{LnFeNb}_{4} \mathrm{O}_{15}$ ( $\mathrm{Ln}=$ rare earth) with the "tetragonal tungsten bronze” (TTB) structure have correlated their room temperature multiferroics properties to the occurrence of barium ferrite parasitic phases. This work presents the elaboration of $\mathrm{Ba}_{2} \mathrm{LaFeNb}_{4} \mathrm{O}_{15}$ and $\mathrm{Ba}_{2} \mathrm{EuFeNb}_{4} \mathrm{O}_{15}$ composite samples with an excess of hematite in the TTB nominal composition. The influence of crystal-chemistry on the phase content and properties of $\mathrm{Ba}_{2} \mathrm{LnFeNb}_{4} \mathrm{O}_{15}$ TTB composites is discussed. A particular focus on the mechanisms related to the in-situ formation of barium ferrite is given. We show that we can control the spurious ferrite phase in TTB multiferroic composites and thus modulate their magnetic response.
\end{abstract}

\section{Key words}

Multiferroics, Tetragonal tungsten bronze, composites 


\section{Introduction}

Multiferroics are materials which exhibit two or more switchable states simultaneously such as polarization, magnetization or strain. The majority of magnetic oxides crystallize with a centrosymmetric space group, which excludes any ferroelectric properties. Also, most of ferroelectric materials do not contain paramagnetic ions. That is why single phase multiferroics that exhibit both ferroelectricity and magnetic order are rare, and usually display only weak magnetoelectric coupling, taking place at low temperature $[1,2,3]$. Recently, new approaches were proposed for the design and the application of new generation storage devices, sensors, actuators, using multiferroics materials $[4,5,6]$. However, the main drawback is that the operating temperatures of the proposed systems are still far below room temperature. More suitable materials are thus needed, and we report in this paper our progress in the elaboration of “TTB” composite multiferroics

Tetragonal tungsten bronze (TTB) niobates (the projection of the structure in a plane perpendicular to the z-axis is given on Fig.1) form an important family of dielectric materials, which exhibit piezoelectric, pyroelectric, ferroelectric and non-linear optic properties. The TTB framework consists of corner-sharing distorted $(\mathrm{Nb}) \mathrm{O}_{6}$ octahedra that define open channels in which are located 9-,12- and 15- coordinated cationic sites. These triangular, square and pentagonal-shaped channels can host several kinds of cations with related variations in physical properties, like non-linear optics, existence of a polar state (...). With the introduction of rare earth in square channels and $\mathrm{Fe}^{3+}$ in the octahedral framework both spontaneous polarization and magnetization were expected at room temperature as proposed by Roth [7] and Krainik [8].

We recently have shown that a barium ferrite parasitic phase was responsible for RT magnetic hysteresis [9]. A relationship between the chemical stability of $\mathrm{Ba}_{2} \mathrm{LnFeNb}_{4} \mathrm{O}_{15}$ 
compounds ( $\mathrm{Ln}=\mathrm{La}, \mathrm{Pr}, \mathrm{Nd}, \mathrm{Sm}, \mathrm{Eu}, \mathrm{Gd})$, the distortions of the TTB framework (induced by the rare earth) and the presence of byproducts was found. Practically, the anionic network does undergo increasing distortions to accommodate small rare earths. Even if these distortions are proofs of the flexibility of the structure, they are not sufficient enough to allow accommodation of the entire amount of small rare earth that the $\mathrm{Ba}_{2} \mathrm{LnFeNb}_{4} \mathrm{O}_{15}$ chemical formulation suggests. Then the excess of rare earth forms a $\mathrm{LnNbO}_{4}$ fergusonite phase, and to preserve electrical neutrality of the TTB matrix, a corresponding amount of iron is not accommodated and forms barium ferrite. It was observed that the dielectric properties (polar state) of BLnFN samples were not significantly altered by the small of that barium ferrite phase.

To go further in our investigation we intend to demonstrate that the magnetic properties of "TTB" composites” can be controlled by adequate chemical processing. Such processing allows inducing the in-situ formation of barium ferrite. In the following, the Ln and Fe substituted TTB structures will be called BLFN (lanthanum) or BEFN (europium), the weight percentage of excess iron oxide being reported as $+\mathrm{X}$ (BEFN+5 for example). 


\section{Experiments}

Reagent grade of $\mathrm{BaCO}_{3}, \mathrm{Fe}_{2} \mathrm{O}_{3}, \mathrm{Nb}_{2} \mathrm{O}_{5}$ and $\mathrm{Ln}_{2} \mathrm{O}_{3}$ of $99.9 \%$ minimum purity were used to prepare, by conventional solid state route, $\mathrm{BLnFN}+\mathrm{X}(\mathrm{Ln}=\mathrm{La}, \mathrm{Eu} ; \mathrm{X}=1 \%, 2 \%, 5 \%)$ samples. Iron oxide (referred to as hematite in the following) excess was added to the stoichiometric mixture of reacting products. These mixtures were ball-milled in absolute ethanol in a planetary grinder. The dried slurries were calcined in a tubular furnace, and the green pellets were sintered at $1340^{\circ} \mathrm{C}$ in an oxygen-rich atmosphere. The resulting ceramics exhibited densities ranging from $91 \%$ to $95 \%$ of the nominal density of the products.

X-ray diffraction data were recorded on a PANalytical X'Pert diffractometer $\left(\mathrm{CuK}_{\alpha}, \lambda\right.$ $=1.5418 \AA$ ) with $25<2 \theta<40^{\circ}$ and a 400 s step of $0.01^{\circ}$ for all the composites pellets.

X-Ray microprobe analyses were performed on a Cameca SX100 apparatus (Operating voltage: $20 \mathrm{kV}$ ).

Dielectric measurements were performed on a Wayne-Kerr 6425 component analyser under dry helium, using gold electrodes, at frequencies ranging from $10^{2}$ to $2.10^{5} \mathrm{~Hz}$.

Magnetic hysteresis loops were obtained on a SQUID magnetometer (MPMS, Quantum Design Inc.). 


\section{Results}

\section{1. $\quad$ X-Ray diffraction patterns}

The diffraction patterns of all composites pellets show that the "pseudo-tetragonal" orthorhombic cell (Pba2 S.G. $n^{\circ} 32$ ) previously observed [9] is maintained. For lanthanum composites, the Bragg diffraction peaks related to the fergusonite $\mathrm{LaNbO}_{4}$ are identified, despite their relative low intensities. A very small broadened contribution is also detected around $34.5^{\circ} 2 \theta$ for BLFN+5 which is attributed to the barium ferrite phase. For europium composites, the relative intensities of Bragg peaks of both parasitic phases increase with the excess of hematite.

\section{2. $\quad \mathrm{XR}$ microprobe analyses}

XR microprobe analyses show that the BLFN sample is perfectly single-phased. For all composites samples, several local analyses show an homogenous cationic composition for the tetragonal bronze. In all the samples except BLFN, small iron-rich areas are detected on the Fe-mapping. These iron-rich areas also have a specific signature (higher $\mathrm{O}$ content) on the O-mapping. Local analyses indicate that they contain a small amount of barium, in agreement with the formula $\mathrm{BaFe}_{12} \mathrm{O}_{19}$ associated with barium ferrite. The iron and oxygen maps get on well together, concerning barium ferrite detection, for all the samples except BLFN (no ferrite) and BEFN+5. In this latter sample, in addition to barium ferrite, an iron-rich phase which does not contain barium is observed. This ironrich phase, contrary to barium ferrite, have no specific signature on the O-mapping. It is likely that this additional iron-rich phase is $\mathrm{Fe}_{2} \mathrm{O}_{3}$, for which the $\mathrm{O} / \mathrm{Fe}$ ratio (1.5) is slightly lower than for $\mathrm{BaFe}_{12} \mathrm{O}_{19}$ (1.58), accounting for the different contrast in the $\mathrm{O}$ mapping.(Figure 3). 


\subsection{Magnetic measurements}

Magnetic hysteresis loops at room temperature (Figure 4) have been measured for all TTB composites. Note that no hysteresis loop was observed for BLFN sample. The lanthanum composites magnetizations at 20000 Oe evolve between 200 and $2900 \mathrm{emu} / \mathrm{mol}$, while for the europium composite magnetizations range from 900 to $3400 \mathrm{emu} / \mathrm{mol}$. With regards to the amount of hematite, magnetizations are systematically higher in europium samples, compared to lanthanum ones. For all samples, the values of remnant magnetization are increasing with respect to the hematite excess. However the magnetization of the BEFN+5 sample appears weaker than it could have been expected when comparing to the BEFN+2 sample. The value of coercive field for lanthanum composites is the same for all samples, i.e. 1000 Oe. Nevertheless the values of coercive field are decreasing with the respect to the hematite excess in the europium series. Since the TTB matrix is able to fully accommodate $\mathrm{La}^{3+}$ ions, while the accommodation of $\mathrm{Eu}^{3+}$ ions is incomplete, the evolution of the coercive field in BELFN composites may be related to Eu doping of the barium ferrite.

\subsection{Dielectric measurements}

BLFN exhibit no dielectric transition down to $80 \mathrm{~K}$ and BEFN is a ferroelectric with a Curie temperature of $440 \mathrm{~K}$. For BLFN+1 sample, the dielectric properties are unchanged and the dielectric losses remain very low until $420 \mathrm{~K}$. The value of the real part of the dielectric constant is decreasing with the increase of the temperature. For BLFN+2 and BLFN+5, the dielectric losses are very high from 240K: a conductivity regime is established and deteriorates the evaluation of the real part of the dielectric constant. In the BLFN+5 sample, a relaxation is observed around $150 \mathrm{~K}$, which is not explained yet. For the three europium composites, the ferroelectric transition is maintained and also occurs at $440 \mathrm{~K}$. The dielectric 
losses increase after the ferroelectric transition in the three composites, similarly to what is observed in BEFN sample. 


\section{Discussion}

The XRD, X-Ray microprobe and dielectric studies show that the TTB matrix is not significantly affected by the introduction of a hematite excess during the elaboration process. The crystal structure, the chemical composition, the dielectric properties of the TTB Matrix, which constitutes the ferroelectric part of these “TTB” composites, are almost unchanged.

Yet the observation of barium ferrite (X-Ray microprobe, XRD) in the BLFN composites indicates that the excess of introduced hematite accommodates some barium, This account for the in-situ formation of the barium ferrite, the magnetic part of the "TTB" composites. This suggests also that the addition of hematite forces the TTB matrix to release some barium from pentagonal tunnels to allow the formation of the ferrite phase.

The magnetic hysteresis loops observed for lanthanum composites, and particularly the identical coercive fields in all the samples, suggests that barium ferrite composition is not varying in these samples. This is not the case for their europium counterparts, in which the coercive field evolves with respect to the excess of hematite, indicating that the chemical composition of the barium ferrite is also varying. This could be correlated to the fact that the accommodation of europium is limited in the TTB matrix. Thus some europium is available for accommodation in the barium ferrite, inducing these coercive field variations.

But the other interesting feature in the europium composite series is the iron oxide phase observed in BEFN+5 sample. Since the magnetization of this sample appear weaker than expected, it supports the hypothesis that this iron oxide phase is $\mathrm{Fe}_{2} \mathrm{O}_{3}$, as hematite is antiferromagnetic at room temperature. From a chemical point of view, the BLFN +5 and $\mathrm{BEFN}+5$ samples are different, since in $\mathrm{BLFN}+5$ only barium ferrite is detected. This could be related to the fact that the formation of barium ferrite requires the release of barium from the TTB matrix. This means that the observation of $\mathrm{Fe}_{2} \mathrm{O}_{3}$ in BEFN5+ sample shows that the 
TTB matrix has a limited ability to empty its channels, i.e. to release barium while some europium vacancies are already present.

Table 1 resumes the physical properties of the "TTB" composites investigated in this work. It is worth noticing that while the dielectric properties remain mostly stable (or even evolve in a positive way for $B L F N+5$ ) with the hematite excess, the magnetization can be controlled by this excess. Moreover the coercive field may be modified, depending on the rare earth introduced in the TTB framework. 


\section{Conclusion}

The crystal-chemical behaviour of $\mathrm{Ba}_{2} \mathrm{LnFeNb}_{4} \mathrm{O}_{15}$ TTBs has been used to develop room temperature multiferroic composites. By adding various excess of hematite, the in-situ formation of barium ferrite was induced. The room temperature magnetic properties of the multiferroic "TTB” composites can be tuned by varying the excess of hematite introduced during the preparation.. Although these composites are elaborated by a conventional solid state process, knowledge of the crystal-chemical behaviour of the TTB matrix allows understanding and controlling this multiferroic system. Such room temperature multiferroic composites, based on TTB phases, may be interesting candidates for the design of devices operating at room temperature. 


\section{Acknowledgements}

The authors want to thanks C. Geneste, C. Meynard and P. Paillard for sample preparation, E. Lebraud for the collection of X-Ray diffraction data. This work is supported

by the European Network of Excellence "FAME" (www.famenoe.net) and the STREP MaCoMuFi (www.macomufi.eu). 


\section{References}

[1] N. A. Hill, A. Filippetti, J. of Magnetism and Magnetic Materials, 242-245, 2002, 976

[2] M. Fiebig, J. of Physics D: Applied Physics, 38, 2005, R123

[3] W. Eerenstein, N. D. Mathur, J. F. Scott, Nature, 442, 2006, 759

[4] V. E. Wood, A. E. Austin, in Magnetoelectric interaction phenomena in crystals, Gordon and Breach, 1975

[5] J. F. Scott, Nature, 6, 2007, 256

[6] M. Bibes, A. Barthélémy, Nature materials, 7, 2008, 425

[7] P. H. Fang, R. S. Roth, J. of Applied Physics, 31(5), 1960, 143

[8] N. N. Krainik, V. A. Isupov, M. F. Bryzhina, A. I. Agranovskaya, Kristallografiya, 9(3), 1964, 352

[9] M. Josse, O. Bidault, M. Maglione and al, Solid State Science, to be published 


\section{Figures}

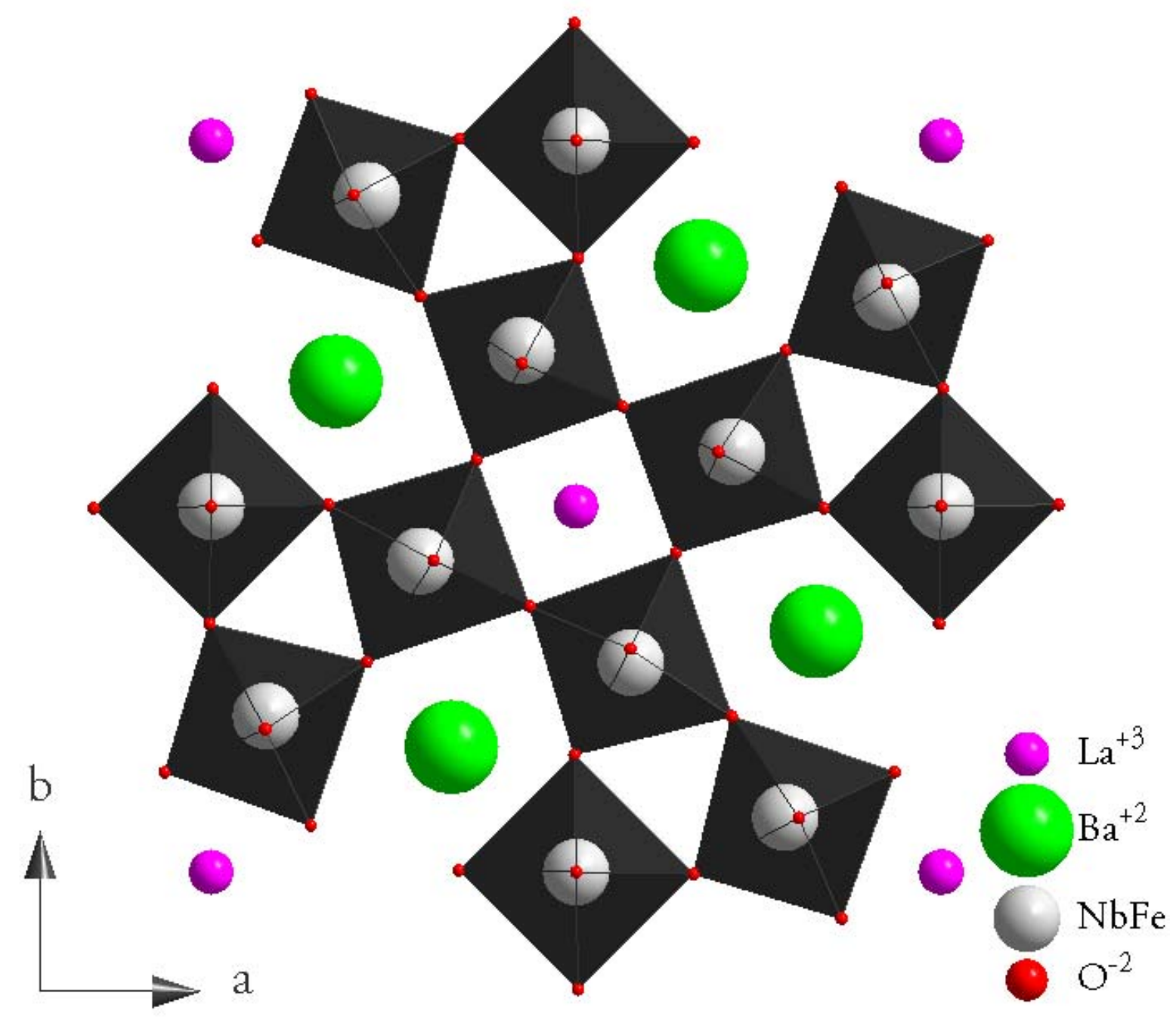

Figure 1: Crystal structure of $\mathrm{Ba}_{2} \mathrm{LnFeNb}_{4} \mathrm{O}_{15}$ viewed along the c axis. 

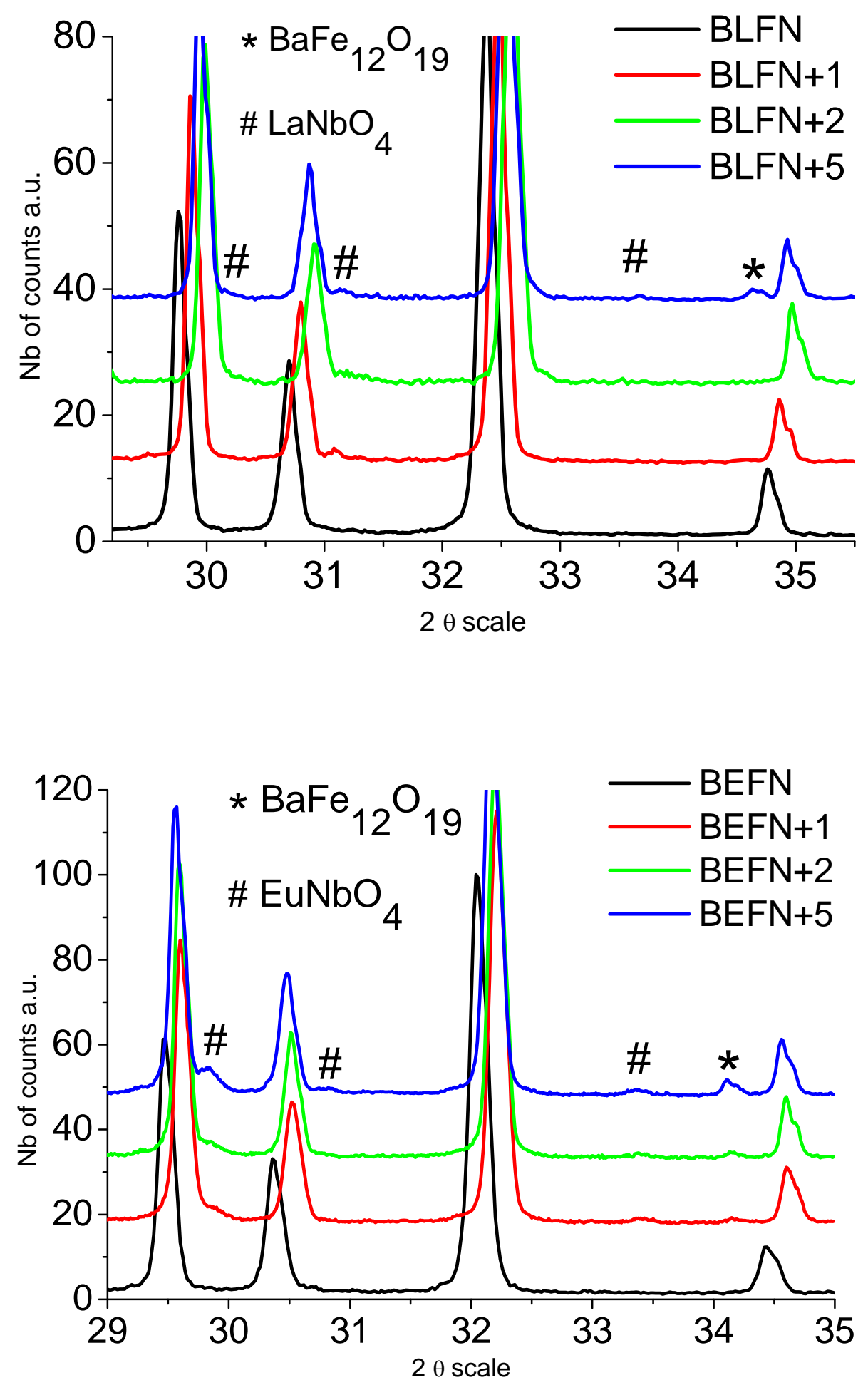

Figure 2 : XRD patterns for BLFN and BEFN composites 


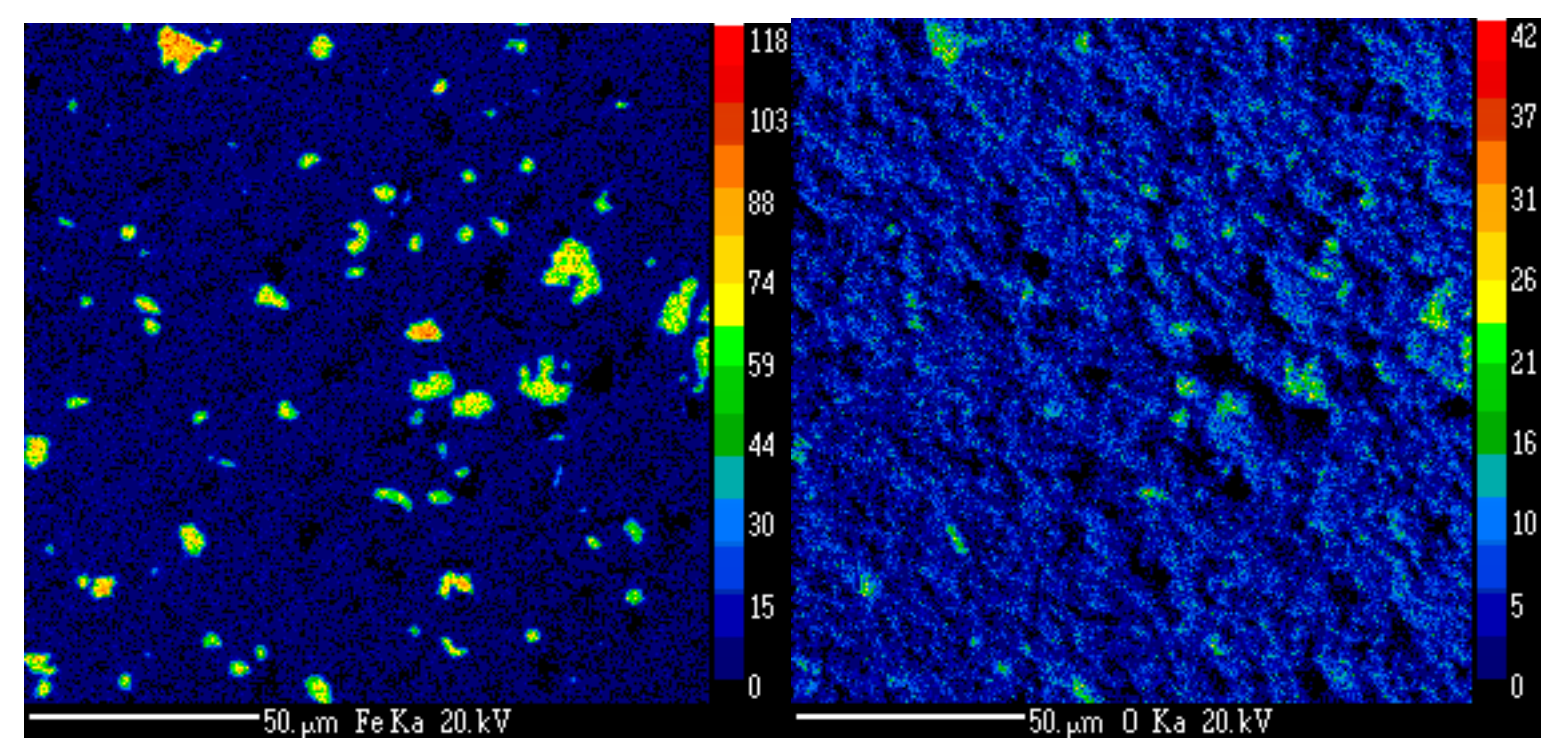

$\mathrm{A}: \mathrm{BLFN}+5$

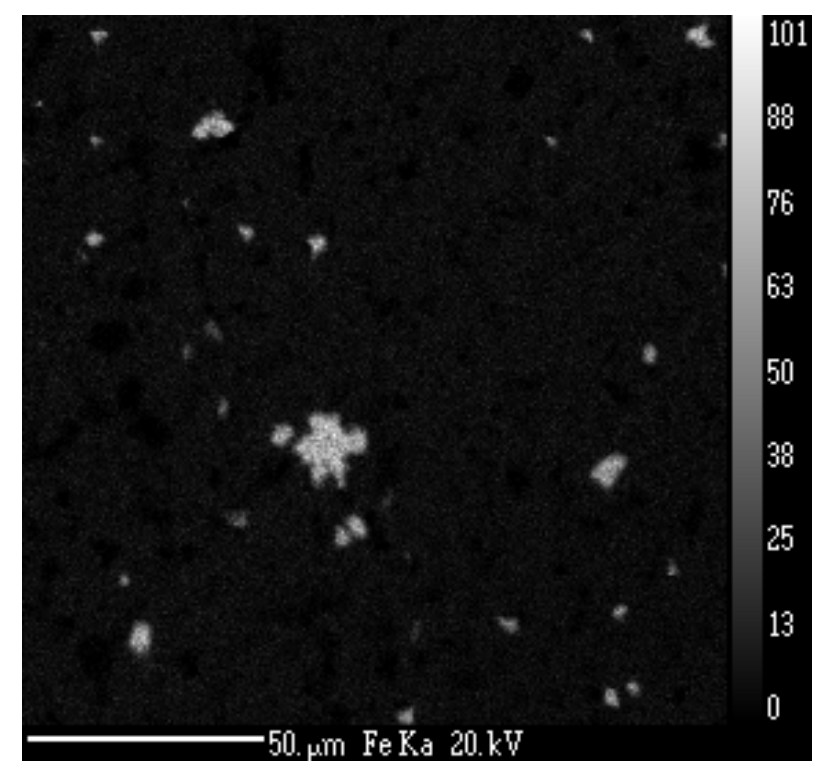

B : BEFN+1, 


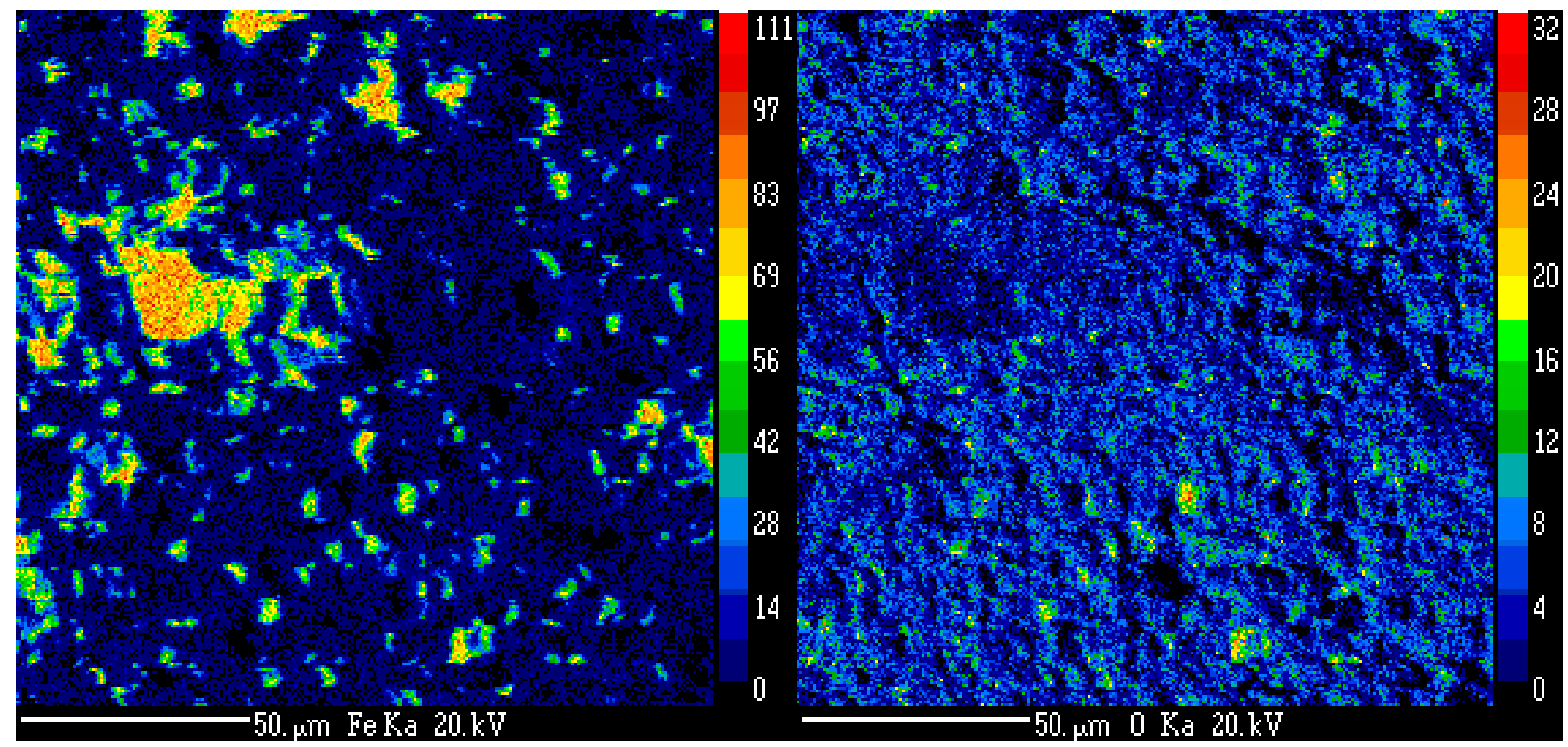

$\mathrm{C}: \mathrm{BEFN}+5$,

Figure 3 : XR-Microprobe analysis, value of Iron and oxygen concentration in BLFN+5 (a), $\mathrm{BEFN}+1$ (b) and BEFN+5(c)

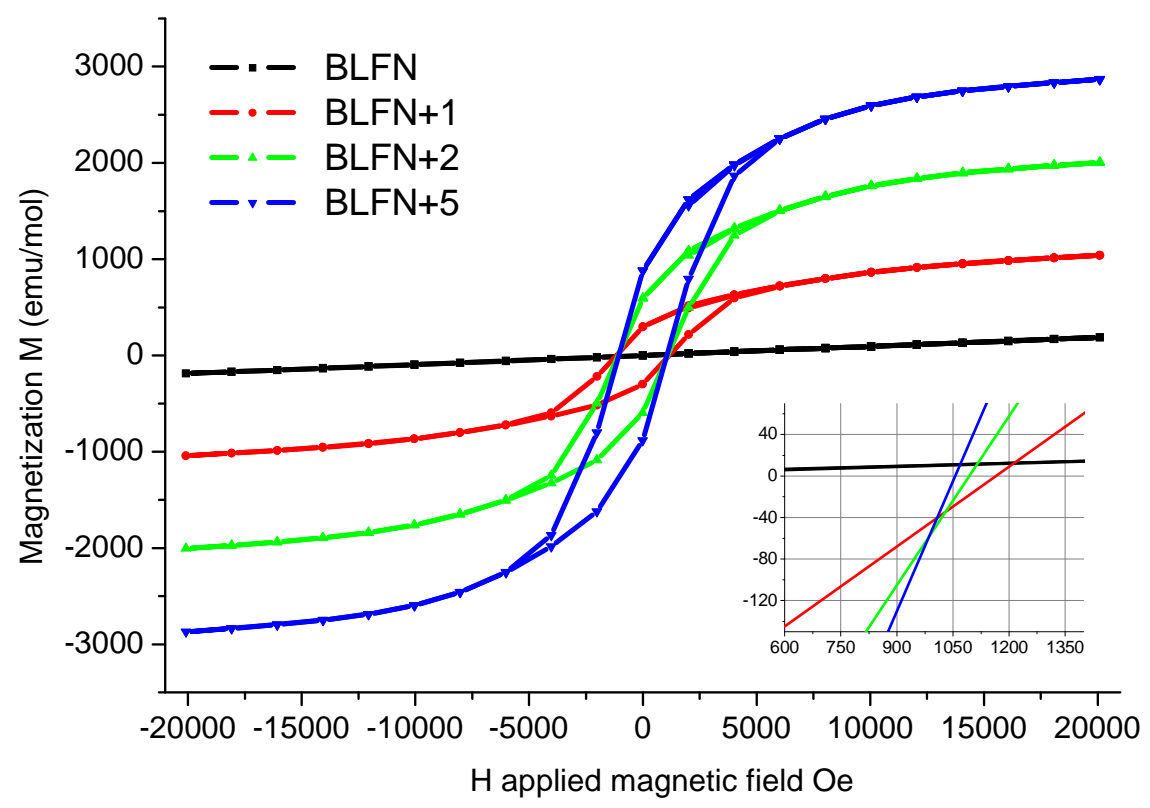




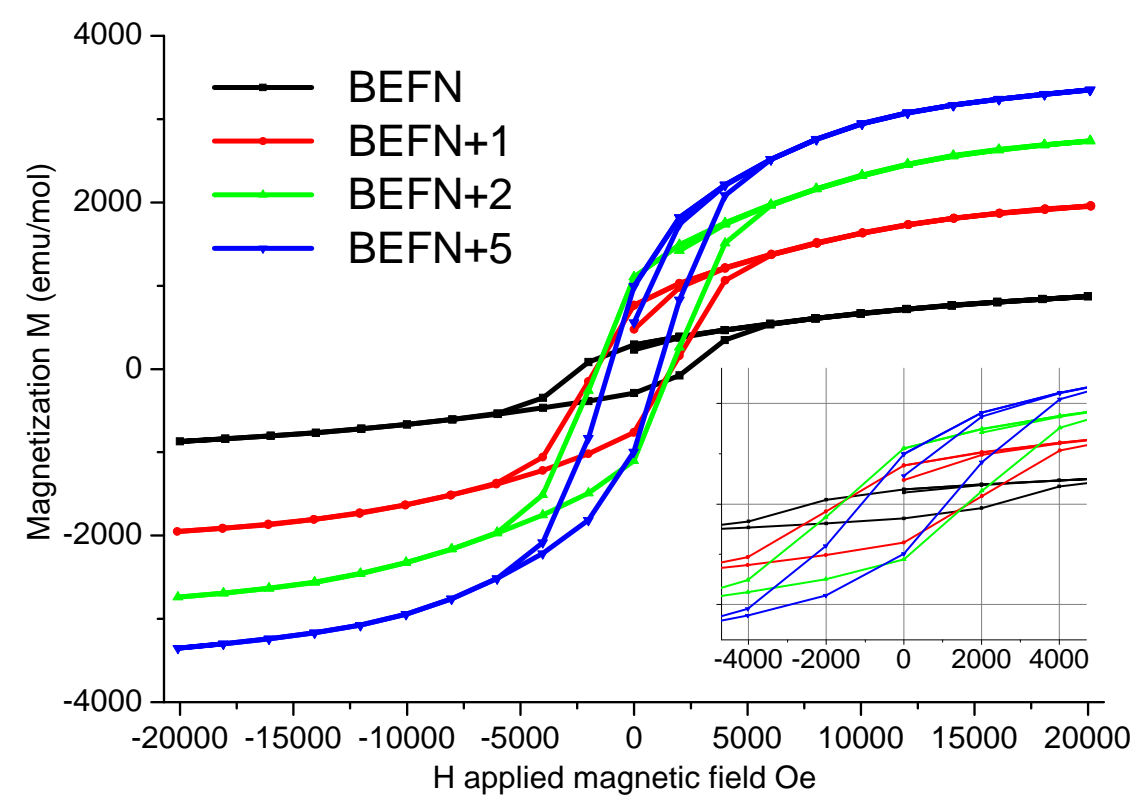

Figure 4: Room Temperature magnetic hysteresis loops in Lanthanum and Europium composites 


\section{Tables}

\begin{tabular}{|c|c|c|c|c|c|}
\hline Composition & $\begin{array}{c}\text { Name of } \\
\text { the } \\
\text { sample }\end{array}$ & $\begin{array}{l}\text { Dielectric } \\
\text { anomaly }\end{array}$ & $\begin{array}{c}\text { Dielectric } \\
\text { losses, } \\
300 \mathrm{~K}, 1 \mathrm{kHz}\end{array}$ & $\begin{array}{c}\text { Magnetization } \\
(300 \mathrm{~K}, 2 \mathrm{~T} \\
\left.\text { emu.mol}^{-1}\right)\end{array}$ & $\begin{array}{l}\text { Coercive } \\
\text { Field } \\
\text { (Oe) }\end{array}$ \\
\hline $\mathrm{Ba}_{2} \mathrm{LaFeNb}_{4} \mathrm{O}_{15}$ & BLFN & N/A & 0.005 & 200 & 0 \\
\hline $\begin{array}{c}\mathrm{Ba}_{2} \mathrm{LaFeNb}_{4} \mathrm{O}_{15} \\
+1 \% \mathrm{Fe}_{2} \mathrm{O}_{3}\end{array}$ & $\mathrm{BLFN}+1$ & N/A & 0.01 & 1000 & 1000 \\
\hline $\begin{array}{c}\mathrm{Ba}_{2} \mathrm{LaFeNb}_{4} \mathrm{O}_{15} \\
+2 \% \mathrm{Fe}_{2} \mathrm{O}_{3}\end{array}$ & $\mathrm{BLFN}+2$ & N/A & 0.03 & 2000 & 1000 \\
\hline $\begin{array}{c}\mathrm{Ba}_{2} \mathrm{LaFeNb}_{4} \mathrm{O}_{15} \\
+5 \% \mathrm{Fe}_{2} \mathrm{O}_{3}\end{array}$ & $\mathrm{BLFN}+5$ & $\begin{array}{c}\text { Relaxation } \\
160 \mathrm{~K}\end{array}$ & 0.21 & 2900 & 1000 \\
\hline $\mathrm{Ba}_{2} \mathrm{EuFeNb}_{4} \mathrm{O}_{15}$ & BEFN & $\begin{array}{c}\text { Ferroelectric } \\
440 \mathrm{~K}\end{array}$ & 0.06 & 900 & 1100 \\
\hline $\begin{array}{c}\mathrm{Ba}_{2} \mathrm{EuFeNb}_{4} \mathrm{O}_{15} \\
+1 \% \mathrm{Fe}_{2} \mathrm{O}_{3}\end{array}$ & $\mathrm{BEFN}+1$ & $\begin{array}{c}\text { Ferroelectric } \\
440 \mathrm{~K}\end{array}$ & 0.14 & 2000 & 1600 \\
\hline $\begin{array}{c}\mathrm{Ba}_{2} \mathrm{EuFeNb}_{4} \mathrm{O}_{15} \\
+2 \% \mathrm{Fe}_{2} \mathrm{O}_{3}\end{array}$ & $\mathrm{BEFN}+2$ & $\begin{array}{c}\text { Ferroelectric } \\
440 \mathrm{~K}\end{array}$ & 0.07 & 2900 & 1600 \\
\hline $\begin{array}{c}\mathrm{Ba}_{2} \mathrm{EuFeNb}_{4} \mathrm{O}_{15} \\
+5 \% \mathrm{Fe}_{2} \mathrm{O}_{3}\end{array}$ & $\mathrm{BEFN}+5$ & $\begin{array}{l}\text { Ferroelectric } \\
\qquad 440 \mathrm{~K}\end{array}$ & 0.27 & 3400 & 2400 \\
\hline
\end{tabular}

Table 1: Physical properties of BLnFN+X composites. 